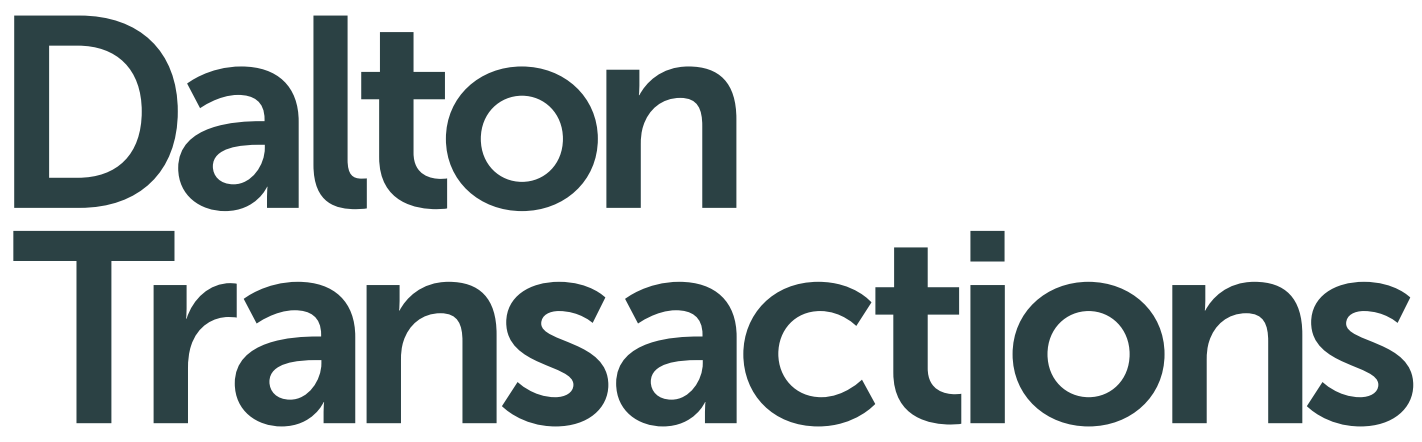

An international journal of inorganic chemistry www.rsc.org/dalton
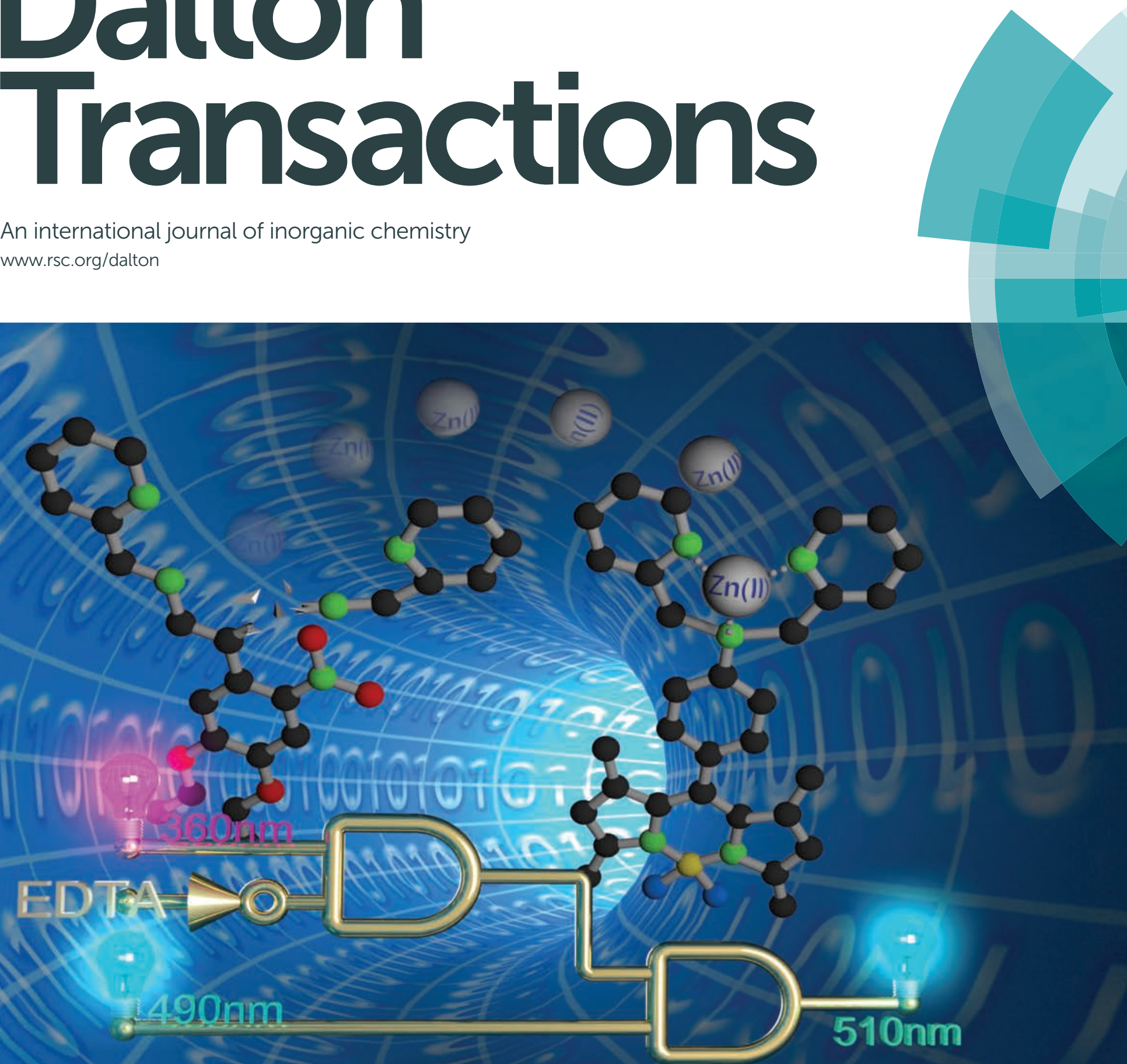

ISSN 1477-9226

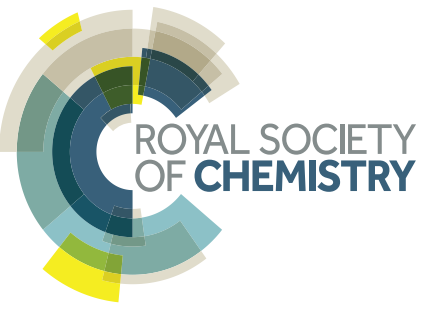

COVER ARTICLE

Akkaya et al.

Modular logic gates: cascading independent logic gates via metal ion signals 
Cite this: Dalton Trans., 2014, 43, 67

\title{
Modular logic gates: cascading independent logic gates via metal ion signals $\dagger$
}

\author{
Esra Tanriverdi Ecik, ${ }^{a, b}$ Ahmet Atilgan, ${ }^{a}$ Ruslan Guliyev, ${ }^{c}$ T. Bilal Uyar, ${ }^{a}$ \\ Aysegul Gumus ${ }^{a, d}$ and Engin U. Akkaya*a,c
}

Received 28th August 2013,

Accepted 27th September 2013

DOI: 10.1039/c3dt52375f

www.rsc.org/dalton

\begin{abstract}
Systematic cascading of molecular logic gates is an important issue to be addressed for advancing research in this field. We have demonstrated that photochemically triggered metal ion signals can be utilized towards that goal. Thus, independent logic gates were shown to work together while keeping their identity in more complex logic designs. Communication through the intermediacy of ion signals is clearly inspired from biological processes modulated by such signals, and implemented here with ion responsive molecules.
\end{abstract}

\section{Introduction}

The field of molecular logic gates continues to flourish since the original conception by de Silva. ${ }^{1}$ Basic Boolean operators now have a large number of molecular equivalents ${ }^{2}$ with various kinds of inputs and outputs. In addition to combinatorial logic, a few examples of sequential logic appeared as well. ${ }^{3}$ However, some troubling questions remain, and shadow the work done in this field. Many in the field are convinced of potential niche applications, most likely in the medical (therapeutic) context. ${ }^{4}$ Even so, advanced functions require an advanced level of logic gate cascading. In the digital electronic elements, cascading of gates can be easily handled as the inputs and outputs are both electrical. In chemical logic gates, the input/output heterogeneity is a major problem towards cascading gates. On the other hand, there are many examples of biological signal cascades, ${ }^{5}$ with messenger molecules, ion signals and metabolic pathways. Thus, it makes most sense to make use of similar intermediary species to link or cascade independent molecular logic gates. Photochemical and reversible $\mathrm{H}^{+}$generation has already been applied in a cascading scheme. $^{6}$

Metal ion signaling seems especially enticing, considering a multitude of literature examples ${ }^{7}$ for "caged" metal ions, and the large variety of possible interactions and a diverse set of

\footnotetext{
${ }^{a}$ UNAM-National Nanotechnology Research Center, Bilkent University, 06800 Ankara, Turkey.E-mail: eua@fen.bilkent.edu.tr; Fax: +90 312-266-4068; Tel: +90 312-290-2450

${ }^{b}$ Department of Chemistry, Gebze Institute of Technology, Kocaeli, 41400, Turkey

${ }^{c}$ Department of Chemistry, Bilkent University, Ankara, 06800, Turkey

${ }^{d}$ Department of Chemistry, Yuzuncu Yil University, Van, 65080, Turkey

$\dagger$ Electronic supplementary information (ESI) available: Experimental details; Synthetic routes; Characterization data; Photophysical parameters. See DOI: 10.1039/c3dt52375f
}

photonic or chemical signals to be produced as outputs. Such compounds are typically metal ion complexes, which, on irradiation with short wavelength light, undergo a photochemical cleavage reaction, releasing metal ions. The release is due to reduced affinity of the cleaved pieces of the ligand for the metal ions in question. Thus, depending on the factors such as the fluence rate of the irradiation, quantum yield of the photochemical reaction, relative affinities of the ligand and the degradation products for the metal ion, a reproducible ion signal can be generated. Molecular logic gates, even in their earliest conception, were mostly chosen among ion responsive molecules, and their response was typically a change in emission intensity or wavelength.

\section{Results and discussion}

In recent work, we reported cascading of logic gates by a chemical reaction. ${ }^{8}$ However, for a broadly applicable cascading scheme, the use of metal ion signals looks more promising. Thus, our first cascaded logic gates are comprised of the caged zinc(II) compound $\mathbf{1}$ and the dipicolylamine (DPA) substituted Bodipy dye 2. The ligand used in compound $\mathbf{1}$ has minor substitution differences with the previously reported compound $^{7 b}$ (and was synthesized in 6 steps from simpler precursors essentially following the literature procedure ${ }^{7 b}$ ). The Bodipy derivative 2 was also synthesized following established protocols $^{9}$ for Bodipy synthesis (ESI $\dagger$ ).

The Bodipy derivative 2 is weakly fluorescent in acetonitrile solutions. The quenching is widely ascribed to the PeT process from the electron rich meso substituent $;{ }^{10}$ however in polar solvents, a dark ICT state may play a role as well. ${ }^{11}$ Ion binding enhances the emission intensity at $510 \mathrm{~nm}$. On the other 
hand, EDTA is a non-selective chelator for many metal ions in aqueous and organic solutions.

Using EDTA as an input, we can devise an INH logic gate in a straightforward way (Fig. 1). Here is how that gate works: irradiation at 360 (input $1=1$ ) results in a $\mathrm{Zn}$ (II) signal only when EDTA is not present (input $2=0$ ). That defines an independently functioning INH gate. Bodipy dye 2 produces photonic output (emission at $510 \mathrm{~nm}$ ) only if there are sufficient free $\mathrm{Zn}$ (II) ions in solution and if the compound is excited at $480 \mathrm{~nm}$. When the two modular molecular logic gates designed this way are placed in the same solution, the two gates are cascaded, i.e., the output $\mathrm{Zn}$ (II) is taken up by the dipicolyl-Bodipy which in turn generates green emission if it is also excited separately at $480 \mathrm{~nm}$. Actual implementation is more successful if instead of $1: 1$ equivalency, more (2 equivalents) caged $\mathrm{Zn}$ (II) compound is added (Fig. 2). When both 1 and 2 were added at $5.0 \mu \mathrm{M}$ concentrations, even at full degradation of the cage, the emission due to 2 is low; this is due to the lower amount of $\mathrm{Zn}$ (II) release on degradation. At 2 equivalents of the cage compound under the same conditions almost $70 \%$ of the fully complexed 2 emission was obtained.

Thus, in the optimal implementation of cascaded INHAND logic modules, the solution initially contains $10.0 \mu \mathrm{M}$ cage-compound 1 (INH module) and $5.0 \mu \mathrm{M}$ compound 2 (AND module). The cascaded gate response is strong, with a very large increase in the emission intensity at $510 \mathrm{~nm}$ (Fig. 3).

Encouraged by the success of the logic gate implementation, we wanted to demonstrate that higher order cascading is also possible (Fig. 5). We previously reported a through space energy transfer for coupled AND logic gates. ${ }^{8}$ The energy transfer at the concentrations used in the study becomes possible only if the two AND logic gate modules are chemically tethered. This is to say that compound 3 can be viewed as two

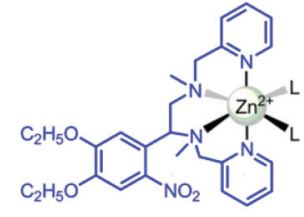

1
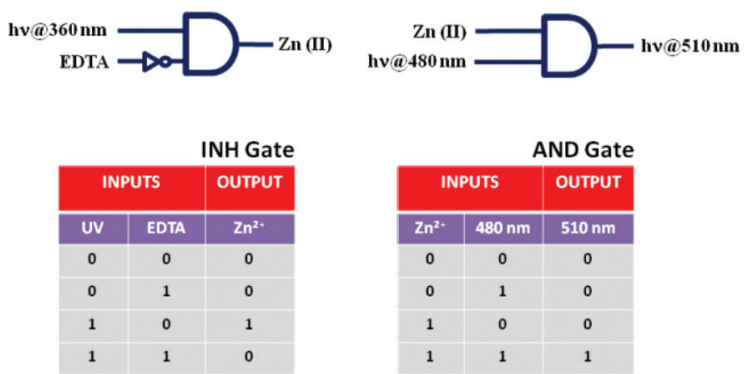

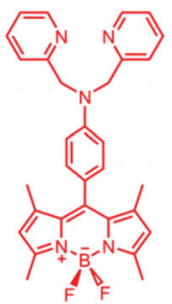

2

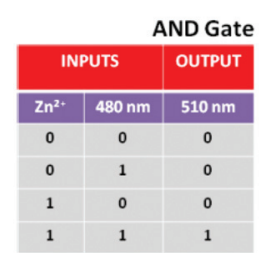

Fig. 1 Independent INH and AND logic gates. Irradiation of the $10.0 \mu \mathrm{M}$ solutions of compound 1 in acetonitrile solutions releases $\mathrm{Zn}($ II) ions, which are chelated by 2 to generate emission signals.

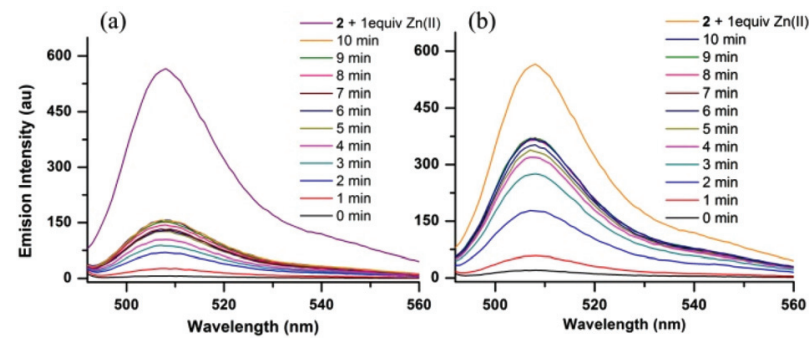

Fig. 2 Fluorescence response of compound 2 upon the uncaging of (a) 1 equivalent and (b) 2 equivalents of cage compound 1 (5.0 $\mu \mathrm{M}$ each) recorded in acetonitrile. Initially compound 2 exhibits no fluorescence (quenched due to the active PET process), irradiation of the solution at $360 \mathrm{~nm}$ resulted in the complete photolysis of 1 which can be followed using the enhanced emission spectrum of compound 2. Highest intensity curves (a-purple, b-orange) represent the maximum emission intensities of 2 which were obtained by the addition of 1.0 equivalent of zinc(॥) cations in the form of triflate salt. $\left(\lambda_{\mathrm{ex}}=480 \mathrm{~nm}\right.$, slit width $=5-2.5$.)

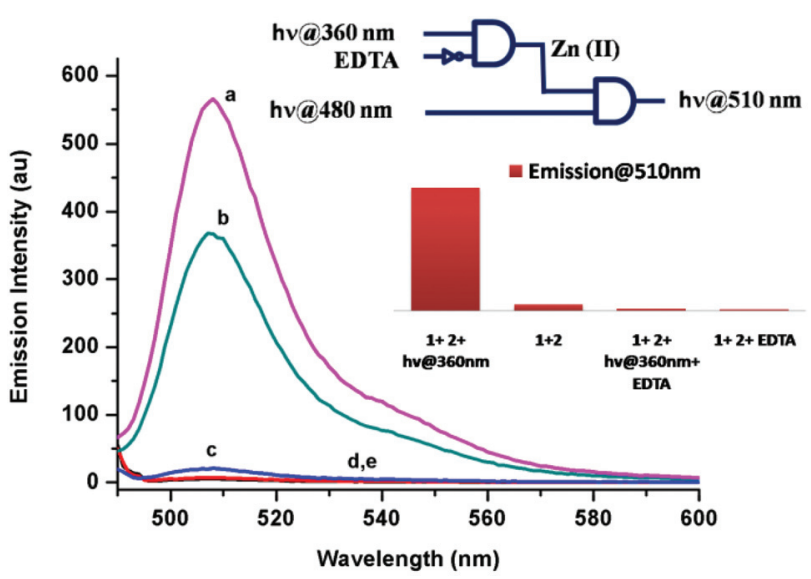

Fig. 3 Cascading of the two independent gates, INH and AND logic gates. (a) The maximum emission intensity of 2 is obtained by the addition of 1 equivalent of zinc(II) triflate salt; (b) irradiation of the $10.0 \mu \mathrm{M}$ solutions of compound 1 in acetonitrile solutions with $360 \mathrm{~nm}$ light releases $\mathrm{Zn}($ II) ions, which are chelated by $2(5.0 \mu \mathrm{M})$ to generate a very strong emission at $510 \mathrm{~nm}$ when excited at $480 \mathrm{~nm}$; (c) $1+2$; (d) $1+2+$ EDTA; (e) the presence of EDTA $(5.0 \mu \mathrm{M})$ reduces the available free $\mathrm{Zn}($ II) significantly, with an expected result of negligible emission from the Bodipy dye.

AND logic gates cascaded by chemical reaction. As the primary AND gate module in compound $\mathbf{3}$ is a dipicolylamine-derivative, we wanted to couple this AND-AND cascade which was shown to function independently previously, with photochemically released $\mathrm{Zn}$ (II) signal. The energy transfer between the AND-AND module is only possible when $\mathrm{Hg}$ (II) ions are added as well; this causes a blue shift in the absorbance spectrum increasing the spectral overlap and hence the efficiency of through space energy transfer (Fig. 4). The absorbance band of the distyryl-Bodipy compound shows a hypsochromic shift of $40 \mathrm{~nm}$ on binding of the mercuric ions. Strong red emission from the AND-AND cascade is also contingent upon the release of $\mathrm{Zn}$ (II), which blocks the PeT quenching operational in the meso-dipicolylaminophenyl substituted Bodipy unit. 


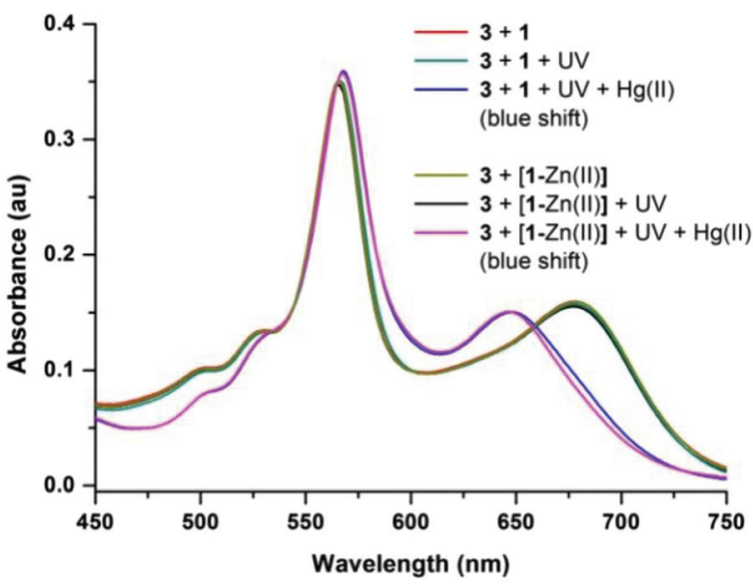

Fig. 4 Absorbance spectra of compound $3(3.0 \mu \mathrm{M})$ recorded in acetonitrile in the presence of compound 1 and $\mathrm{Hg}(\mathrm{II})$ cations $(3.0 \mu \mathrm{M}$, $18.0 \mu \mathrm{M}$, respectively). Also note that $[1-\mathrm{Zn}(\mathrm{II})]$ refers to the caging ligand alone, i.e., without the $\mathrm{Zn}(\mathrm{II})$ ions.

The dissociation constants of the dipicolylamine $(2.1 \times$ $10^{-8} \mathrm{M}$, in acetonitrile $\left.{ }^{2 b}\right)$ and for the $1 / \mathrm{Zn}$ (II) complexes $(2.3 \times$ $10^{-13} \mathrm{M}$ in aqueous medium ${ }^{7 b}$ ) are supportive of the photoinduced ion migration. The use of selective ligands minimizes any chances for crosstalk between the gate inputs in solution. Thus, 3.0 $\mu \mathrm{M}$ solutions of compound $\mathbf{1}$ and compound 3, when excited at $360 \mathrm{~nm}$ light, set off a sequence of events, which are in accordance with cascaded INH-AND-AND gates (Fig. 6).

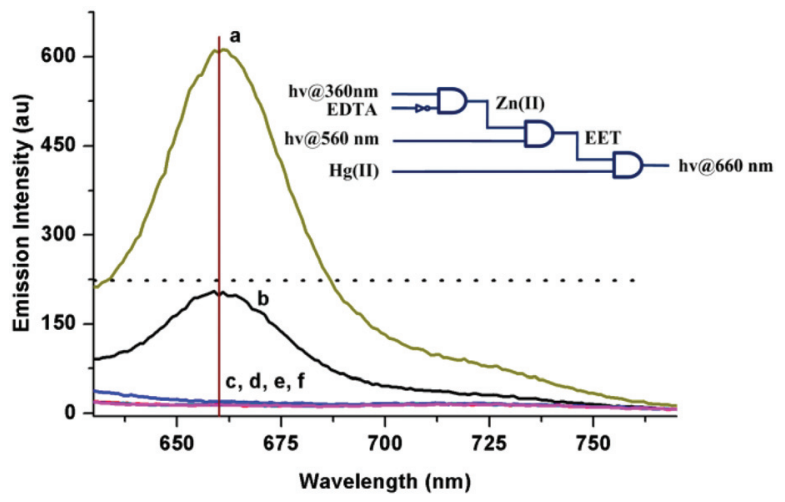

Fig. 6 Spectral response of the cascaded INH-AND-AND logic modules: (a) emission spectra of $3(3.0 \mu \mathrm{M})$ in acetonitrile in the presence of 1 (+hv@360 nm) and $\mathrm{Hg}(\mathrm{II})$ ions (3.0 $\mu \mathrm{M}, 18.0 \mu \mathrm{M}$, respectively); (b) $3+[1-\mathrm{Zn}(\mathrm{I})]+$ $\mathrm{Hg}(\mathrm{II})+\mathrm{hva} 360 \mathrm{~nm}$; (c) $3+1+$ hva360 nm; (d) $3+1$; (e) $3+[1-\mathrm{Zn}(\mathrm{II})]+$ hva360 nm; (f) $3+[1-Z n(I)]$. Also note that $[1-Z n(I)]$ refers to the caging ligand alone, i.e., without the $\mathrm{Zn}(I)$ ions. All solutions were excited at $560 \mathrm{~nm}$.

\section{Conclusion}

While we are cognizant of the fact that chemical analogues of the electronic logic gates do not need to follow the same developmental stages, it is clear that advanced information processing at the molecular level will require a set of modular logic gates, which can talk to each other by exchanging inputs and outputs. Some homogeneity in the choice of inputs and outputs will certainly help in establishing the modularity of the logic gates. Metal ion signals may be a promising choice. In biological systems, ion signals, together with small

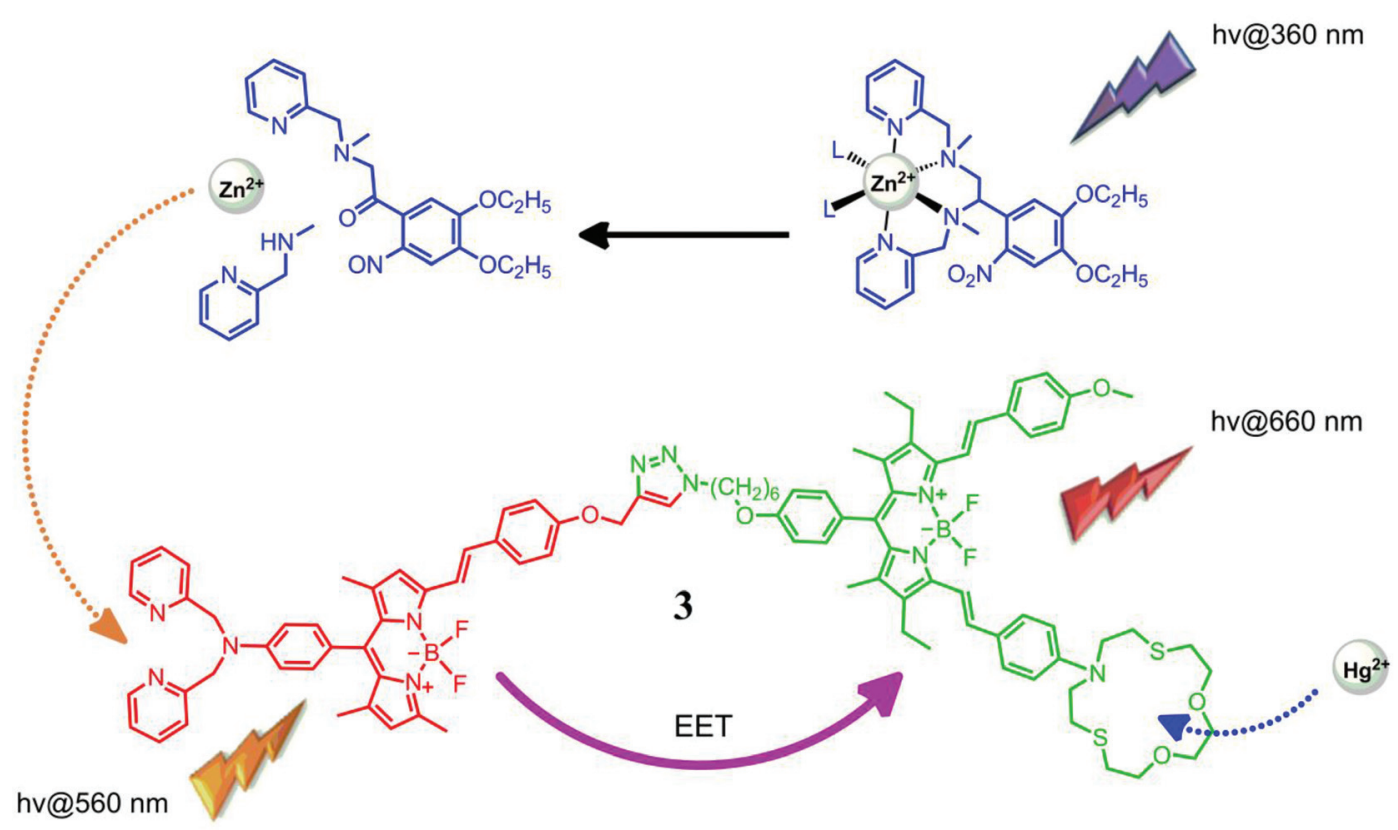

Fig. 5 Cascaded logic modules: the Bodipy dye on the left is weakly emissive due to PeT. On Zn(I) ion complexation, one or more non-radiative pathways become inoperative. Excited state energy is then transferred to the longer wavelength distyryl-Bodipy. This dye becomes strongly emissive only if energy transfer is possible and $\mathrm{Hg}(\mathrm{II})$ in addition to $\mathrm{Zn}(\mathrm{I})$ is made available in the solution. The result is the AND-AND cascade. Photochemical generation of zinc ions, in turn, incorporates the first gate as well, resulting in the INH-AND-AND cascade. 
molecule fluxes, are to a great extent responsible for initiating and maintaining many important processes essential to life itself. Thus, we feel cautiously optimistic that controlled ion fluxes may indeed play an important role in modular assembly of molecular information processors designed and implemented for a particular task in mind.

\section{Acknowledgements}

The authors gratefully acknowledge support from TUBITAK in the form of a postdoctoral scholarship to E. T. Ecik and R. Guliyev and a doctoral scholarship to T. B. Uyar.

\section{Notes and references}

1 A. P. de Silva, H. Q. N. Gunaratne and C. P. McCoy, Nature, 1993, 364, 42.

2 (a) J. Andreasson and U. Pischel, Chem. Soc. Rev., 2010, 39, 174; (b) O. A. Bozdemir, R. Guliyev, O. Buyukcakir, S. Selcuk, S. Kolemen, G. Gulseren, T. Nalbantoglu, H. Boyaci and E. U. Akkaya, J. Am. Chem. Soc., 2010, 132, 8029; (c) A. P. de Silva and S. Uchiyama, Nat. Nanotechnol., 2007, 2, 399; (d) K. Kaur, N. Singh, D. Cairns and J. F. Callan, Org. Lett., 2009, 11, 2229; (e) H. Komatsu, S. Matsumoto, S. Tamaru, K. Kaneko, M. Ikeda and I. Hamachi, J. Am. Chem. Soc., 2009, 131, 5580; (f) K. Szacilowski, Chem. Rev., 2008, 108, 3481; (g) T. Gupta and M. E. Van der Boom, Angew. Chem., Int. Ed., 2008, 47, 5322; (h) A. P. de Silva and S. Uchiyama, Nat. Nanotechnol., 2007, 2, 399; (i) U. Pischel, Angew. Chem., Int. Ed., 2007, 46, 4026; (j) D. Margulies, G. Melman and A. Shanzer, J. Am. Chem. Soc., 2006, 128, 4865; (k) D. Margulies, C. Felder, G. Melman and A. Shanzer, J. Am. Chem. Soc., 2007, 129, 347; (l) S. Kou, H. N. Lee, D. van Noort, K. M. K. Swamy, S. H. Kim, J. H. Soh, K.-M. Lee, S.-W. Nam, J. Yoon and S. Park, Angew. Chem., Int. Ed., 2008, 47, 872.

3 (a) G. Ruiter and M. E. van der Boom, Acc. Chem. Res., 2011, 44, 563; (b) G. Ruiter, E. Tartakovsky, N. Oded and M. E. van der Boom, Angew. Chem., Int. Ed., 2010, 49, 169; (c) U. Pischel and J. Andreasson, New J. Chem., 2010, 34, 2701; (d) G. de Ruiter, L. Motiei, J. Choudhury, N. Oded and M. E. van der Boom, Angew. Chem., Int. Ed., 2010, 49, 4780; (e) R. Baron, A. Onopriyenko, E. Katz, O. Lioubashevski, I. Willner, S. Wang and H. Tian, Chem. Commun., 2006, 2147.
4 (a) U. Pischel, J. Andreasson, D. Gust and V. F. Pais, Chem. Phys. Chem. Rev., 2013, 14, 28; (b) S. Erbas-Cakmak, A. Bozdemir, Y. Cakmak and E. U. Akkaya, Chem. Sci., 2013, 4, 858; (c) S. Ozlem and E. U. Akkaya, J. Am. Chem. Soc., 2009, 131, 48; (d) R. J. Amir, M. Popkov, R. A. Lerner, C. F. Barbas III and D. Shabat, Angew. Chem., Int. Ed., 2005, 44, 2 .

5 (a) E. Katz, V. Bocharova and M. Privman, J. Mater. Chem., 2012, 22, 8171; (b) N. Graf and R. Kramer, Chem. Commun., 2006, 4375.

6 S. Silvi, E. C. Constable, C. E. Housecroft, J. E. Beves, E. L. Dunphy, M. Tomasulo, F. M. Raymo and A. Credi, Chem.-Eur. J., 2009, 15, 178.

7 (a) P. Klan, T. Solomek, C. G. Bochet, A. Blanc, R. Givens, M. Rubina, V. Popik, A. Kostikov and J. Wirz, Chem. Rev., 2013, 113, 119; (b) H. M. D. Bandara, D. P. Kennedy, E. Akin, C. D. Incarvito and S. C. Burdette, Inorg. Chem., 2009, 48, 8445; (c) G. C. R. Ellis-Davies, Chem. Rev., 2008, 108, 1603; (d) A. Pelliccioli and J. Wirz, Photochem. Photobiol. Sci., 2002, 1, 441.

8 R. Guliyev, S. Ozturk, Z. Kostereli and E. U. Akkaya, Angew. Chem., Int. Ed., 2011, 50, 9826.

9 (a) N. Boens, V. Leen and W. Dehaen, Chem. Soc. Rev., 2012, 1130; (b) G. Ulrich, R. Ziessel and A. Harriman, Angew. Chem., Int. Ed., 2008, 47, 1184; (c) R. Ziessel, G. Ulrich and A. Harriman, New J. Chem., 2007, 31, 496; (d) A. Loudet and K. Burgess, Chem. Rev., 2007, 107, 4891; (e) S. Atilgan, T. Ozdemir and E. U. Akkaya, Org. Lett., 2010, 12, 4792; $(f)$ S. Erbas, A. Gorgulu, M. Kocakusakogullari and E. U. Akkaya, Chem. Commun., 2009, 4956; (g) O. A. Bozdemir, S. Erbas-Cakmak, O. O. Ekiz, A. Dana and E. U. Akkaya, Angew. Chem., Int. Ed., 2011, 50, 10907.

10 (a) T. Kobayashi, T. Komatsu, M. Kamiya, C. Campos, M. González-Gaitán, T. Terai, K. Hanaoka, T. Nagano and Y. Urano, J. Am. Chem. Soc., 2012, 134, 11153; (b) T. Matsumoto, Y. Urano, T. Shoda, H. Kojima and T. Nagano, Org. Lett., 2007, 9, 3375; (c) H. Sunahara, Y. Urano, H. Kojima and T. Nagano, J. Am. Chem. Soc., 2007, 129, 5597; (d) Y. Gabe, T. Ueno, Y. Urano, H. Kojima and T. Nagano, Anal. Bioanal. Chem., 2006, 386, 621; (e) Y. Gabe, Y. Urano, K. Kikuchi, H. Kojima and T. Nagano, J. Am. Chem. Soc., 2004, 126, 3357.

11 (a) K. Rurack and U. Resch-Genger, Chem. Soc. Rev., 2002, 31, 116; (b) K. Rurack, M. Kollmannsberger, U. ReschGenger and J. Daub, J. Am. Chem. Soc., 2000, 122, 968; (c) M. Kollmannsberger, K. Rurack, U. Resch-Genger and J. Daub, J. Phys. Chem. A, 1998, 102, 10211. 